\title{
BIM IMPLEMENTATION IN THE PRACTICE OF ARCHITECTURE IN TRINIDAD AND TOBAGO
}

\author{
Leighton Ellis $^{1 *}$, Hector Martin² and Marlon Charles ${ }^{3}$ \\ ${ }^{1}$ Faculty of Engineering, The University of the West Indies, Jamaica \\ ${ }^{2,3}$ Faculty of Engineering, The University of the West Indies, Trinidad \\ ${ }^{1}$ Email: leighton.ellis@uwimona.edu.jm *(Corresponding author) \\ ${ }^{2}$ Email: hector.martin@sta.uwi.edu \\ ${ }^{3}$ Email: imarloncharles@gmail.com
}

\begin{abstract}
Building Information Modelling (BIM) is the latest innovation in Computer Aided Design (CAD) technology. A strong awareness exists amongst architects concerning the benefits of BIM, however they are equally hesitant to use such tools given the associated negative factors such as cost of training. Other external factors such as the construction market and customer requirements also pose barriers to implementation. The findings of this study provide context for understanding how BIM is used in the practice of Architect in Trinidad and Tobago (T\&T). It can be used as a starting point to develop future research into how this technology can be effectively implemented in the practice of Architecture and the wider local construction industry. The findings of the study highlight the need to formulate a strategy for the implementation of BIM and the creation of an appropriate supportive environment for its use in the local construction industry. This requires collaboration from all stakeholders, private and public, to invest and support the development of the necessary policy and standards for BIM implementation, including technical training in the use of software and training in the management of its processes in practice.
\end{abstract}

Keywords: Architecture; Building information modelling, BIM, Construction industry, Virtual model.

https://doi.org/10.47412/MXGQ9564

\section{Introduction}

Building Information Modelling (BIM) is the latest innovation in Computer Aided Design (CAD) technology. It is a term used to describe computer generated virtual models of buildings that simulate real world physical properties that automatically provide feedback of conflicts and redundancies [1]. Data can be quickly and easily extracted from the model to aid in cost, time, quality control, and providing a visual representation of these elements.

The acronym BIM is used to describe either the process of making an information model of a building (Building Information Modelling) or the product itself (Building Information Model). In the construction industry both meanings are accepted and the term BIM is used interchangeably as either a verb or a noun [2]. BIM represents a significant jump in technology for design management; its capacity extends beyond the documentation and visual representation of a building to analysis, management and computation of information. It is a common misconception that BIM is a particular brand of software. The term BIM describes a framework or common 
platform for working in a computer generated virtual environment where various software application and information technology (IT) tools can be used to design buildings [3], by a variety of consultants. BIM differs from the previous versions of CAD technology in that users input parameters for example, the thickness of a concrete slab, into the software in order to generate a visual representation of an object instead of drawing the object using vector coordinates. Figure 1 shows an example of an advanced BIM model.

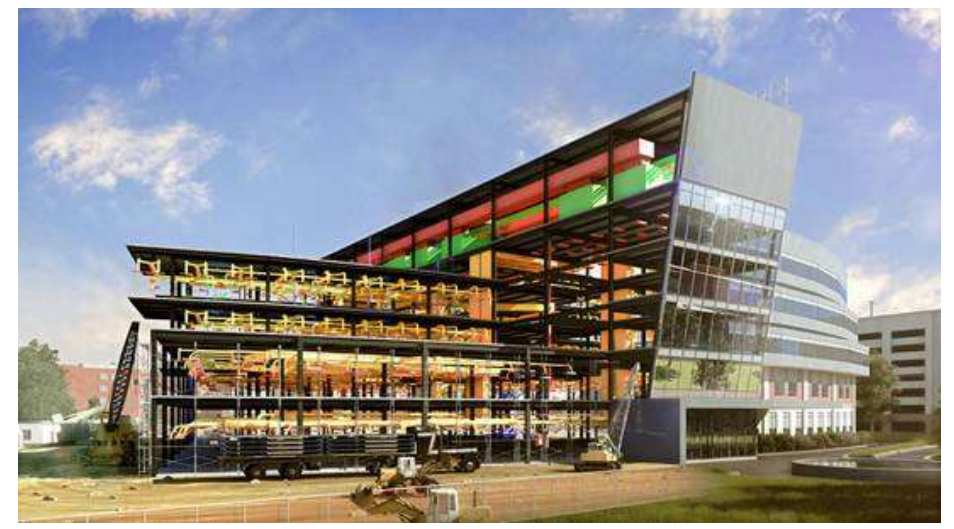

Figure 10: Building information model (BIM)

Source: PRUDECON, 2018

The benefit of this approach to the design process is that the parameters of an object can be quickly and easily modified to change the visual representation of the information. Additionally, BIM gives users the ability to analyse the physical relationship between design elements for example, curtain walls, columns and beams because it simulates real world properties such as density or transparency of these objects in a three dimensional (3D) virtual environment. Few critics deny that BIM will be the standard for building information management in the near future because of its many benefits over previous CAD technology. However, its adoption has been slow in the global construction industry [4] and in research thus far the principal focus has been on the implementation of BIM technology throughout the various stages of a project and the challenges related to its adoption and education [5]. Another common theme is the history and evolution of construction drawing and the variety of software used over time [6]. More recent studies, however, go a step further to examine more specific uses of BIM such as energy management and performance assessment [5]. There is limited studies affecting the adoption of BIM as such this research focuses specifically on the use of BIM in the practice of architecture in Trinidad and Tobago (T\&T).

\subsection{Research Aim and Objectives}

$\mathrm{BIM}$ is an emerging technology that has been used successfully in many developed and developing countries to improve the efficiency, quality and cost effectiveness of the design and construction of buildings. Despite several companies in T\&T using this technology, there is insufficient data on its implementation to determine its benefits to the local construction industry. This research proposes that there are a variety of factors that influence BIM implementation. 
The aim of this study is to assess the factors that influence the implementation of BIM in the practice of Architecture in the Trinidad and Tobago construction industry.

The objectives are therefore to:

1. Assess the scope and extent of implementation of BIM in the practice of Architecture in T\&T;

2. Identify the challenges and benefits of employing BIM in the practice of architecture in $\mathrm{T} \& \mathrm{~T}$;

3. Identify and assess cultural attitudes affecting the shift to a BIM workflow in the practice of architecture in $\mathrm{T} \& \mathrm{~T}$.

The significance of this research is to pioneer and advance research into BIM, in order to improve the practice of architecture and the approach to construction in T\&T. This project will focus on the body of Registered Architects in T\&T in order to gain an understanding of the factors that influence the use of BIM. Analysis will be based on research information and data collected from the period 2004-2017.

\section{Methodology}

At the time of this study, there were no primary sources of research in this field specific to the context of Trinidad and Tobago. Therefore, this research will serve as a contextual study.

Qualitative research methods were used to investigate the factors influencing the implementation of BIM in the practice of architecture in Trinidad and Tobago. The general research approach is inductive and was informed by the exploratory nature of the research question [7]. The research question explores the current dissemination of the emerging BIM process, within this specific geographic, economic and social context of Trinidad and Tobago. Qualitative data was primarily collected through a survey that was administered online to a sample of the local architecture population. The findings were analyzed using descriptive statistics and cross tabulation to determine themes and patterns that can give a description of the current status of BIM implementation.

The population focused on Architects registered with the Board of Architecture of Trinidad and Tobago (BOATT). Due to the cultural ambivalence to participating in research, it is very difficult to collect information from people who work in the construction industry in Trinidad and Tobago. Therefore, the strategy for collecting the data took into consideration the potential reluctance of local architects to participate in the study. In order to collect data for this research is was necessary to persuade the architects in the industry that the research would be beneficial to their practice.

Thus, this study was also conducted through the support of the Trinidad and Tobago Institute of Architects (TTIA) as an initiative to improve the awareness of BIM technology to its members. The TTIA is a group separate from the BOATT that promotes the practice of architecture locally. The TTIA agreed to assist the study by sending the questionnaire on behalf of the researcher to its member database. The information gathered from the study will also be made available to the institute and its members. 


\subsection{Focus group and on-line survey}

The population comprised of Architects registered by the Board of Architecture of Trinidad and Tobago (BOATT) as at the 31st March 2015. According to the Trinidad Gazette VOL.52 NO. 5, dated 31st March 2015, there were a total of 75 Registered Architects. All 75 registered Architects were emailed a questionnaire and 38 responded at a rate of $51 \%$.

A closed ended survey was the primary instrument for data collection. The development of the survey was supported by two other instruments namely as focus group discussion and a pilot survey. These two methods contributed to the validity of the final survey instrument. The pilot served to field-test the survey with a group of non-registered architects - selected from retired professionals, and soon to be registered architecture graduates. The focus group provided contextual information on the general attitudes towards BIM locally, as well as an overview of the status of implementation. This data was useful in designing and framing the open-ended questions of the survey; contributing to the validity of the survey [8].

The final survey was administered using SurveyMonkey, which is an online survey medium for administering customized surveys. The web-based interface of SurveyMonkey is very user friendly for both creating and responding to a survey [9]. SurveyMonkey regularly suggested phasing for questions it detects to be similar to ones in their database, which are verified and validated to reduce bias and ambiguity. The qualitative research approach, which entailed the use of a qualitative survey and analysis of the data using descriptive statistics and cross tabulation, was the most appropriate method for the exploratory research on the factors affecting BIM implementation in Trinidad and Tobago.

\section{Data Analysis}

Demographic information on respondents for example, length of practice, was collated and analyzed using descriptive statistics [10]. Cross tabulation was used to analyzed the survey data to assess the relationship between the variables; in this case the architects and the factors influencing their use of BIM locally. This analysis was conducted using the statistical software, IBM SPSS version 22 .

A total of 41 responses were collected using targeted sampling. In several cases more than one architect worked together in a firm, where one or more response was obtained. Data was first sorted by company name to identify similarities between responses from the same firm. It was observed that there was no significant difference between participants' responses from the same firm regarding the perception and use of BIM.

The majority of respondents were either very familiar (62\%) or somewhat familiar (29\%) with the term Building Information Modelling (BIM), however, the majority of respondents (55\%) had never employed BIM on a project. Additionally, the majority of respondents indicated that they currently do not use BIM (66\%). Base on the data from the survey, $21 \%$ of respondents have tried $\mathrm{BIM}$ at some point and decided not to use it on subsequent projects.

Table 1 shows, Architects who were somewhat familiar with the BIM were more than 9 times as likely $(66.1 \%)$ to report that they have used the software for less than $5 \%$ of projects than those who were very familiar with the system $(7.7 \%)$. 
Table 24: Familiarity with BIM and percentage of projects

\begin{tabular}{|c|c|c|c|c|c|}
\hline & & & \multicolumn{2}{|c|}{$\begin{array}{l}\text { Are you familiar with the term } \\
\text { Building Information Modelling } \\
\text { (BIM)? }\end{array}$} & \multirow[b]{2}{*}{ Total } \\
\hline & & & $\begin{array}{l}\text { Yes, very } \\
\text { familiar }\end{array}$ & $\begin{array}{c}\text { Somewhat } \\
\text { familiar }\end{array}$ & \\
\hline \multirow{10}{*}{$\begin{array}{l}\text { What percentage of } \\
\text { projects have you used } \\
\text { BIM? }\end{array}$} & Less than $5 \%$ & Count & 1 & 4 & 5 \\
\hline & & $\begin{array}{l}\% \text { within Are you familiar } \\
\text { with the term Building } \\
\text { Information Modelling } \\
\text { (BIM)? }\end{array}$ & $7.7 \%$ & $66.7 \%$ & $26.3 \%$ \\
\hline & $5 \%-25 \%$ & Count & 4 & 0 & 4 \\
\hline & & $\begin{array}{l}\% \text { within Are you familiar } \\
\text { with the term Building } \\
\text { Information Modelling } \\
\text { (BIM)? }\end{array}$ & $30.8 \%$ & $0.0 \%$ & $21.1 \%$ \\
\hline & $25 \%-50 \%$ & Count & 1 & 0 & 1 \\
\hline & & $\begin{array}{l}\% \text { within Are you familiar } \\
\text { with the term Building } \\
\text { Information Modelling } \\
\text { (BIM)? }\end{array}$ & $7.7 \%$ & $0.0 \%$ & $5.3 \%$ \\
\hline & $50 \%-75 \%$ & Count & 1 & 1 & 2 \\
\hline & & $\begin{array}{l}\% \text { within Are you familiar } \\
\text { with the term Building } \\
\text { Information Modelling } \\
\text { (BIM)? }\end{array}$ & $7.7 \%$ & $16.7 \%$ & $10.5 \%$ \\
\hline & $75 \%-100 \%$ & Count & 6 & 1 & 7 \\
\hline & & $\begin{array}{l}\% \text { within Are you familiar } \\
\text { with the term Building } \\
\text { Information Modelling } \\
\text { (BIM)? }\end{array}$ & $46.2 \%$ & $16.7 \%$ & $36.8 \%$ \\
\hline \multirow[t]{2}{*}{ Total } & & Count & 13 & 6 & 19 \\
\hline & & $\begin{array}{l}\% \text { within Are you familiar } \\
\text { with the term Building } \\
\text { Information Modelling } \\
\text { (BIM)? }\end{array}$ & $100.0 \%$ & $100.0 \%$ & $100.0 \%$ \\
\hline
\end{tabular}

At the opposite end of the spectrum that represents full usage, those who were very familiar were more than twice as likely (46.2\%) to use the software for between $75-100 \%$ of their projects than those who were somewhat familiar $(16.7 \%)$.

One architect who was somewhat familiar with BIM reported using the software for 50-75\% of his/her projects.

The results suggest that as long as an architect is very familiar with the software, it would result in various levels of use. When the opposite ends of the usage levels are examined, those who are somewhat familiar would be more likely to use the software for less than $5 \%$ of their projects and those who are very familiar are more likely would be more likely to us it in $75-100 \%$ of their projects.

Most BIM users (35.3\%), perceived that unwillingness to change methods and practices were the biggest barrier to BIM adoption in T\&T. The second most identified reason was the cost of software and training (29.4\%), while other reasons such as lack of awareness (17.6\%) and client demands (11.8\%) were also thought of as barriers to BIM adoption.

Table 2 shows, Architects who indicated that the cost of software and training was the biggest barrier were more likely (80\%) to use BIM in less than $25 \%$ of projects than those who cited client demands (50\%) and unwillingness to change methods and practices as a barrier (33.3\%)

Upon examining the responses from the architects who used BIM in $75-100 \%$ of their projects, it was found that outside of the one person who cited other, those who cited, lack of awareness, 
were more likely $(66.7 \%)$ to fall within this category than those who cited unwillingness to change methods and practices $(50 \%)$ and cost of software training (20\%) and client demands (0\%).

The data suggest that those who considered lack of awareness as the major factor would be more likely to use the programme in a larger proportion of their projects of and those who consider cost of software and training as a major barrier would be more likely to use the programme in a smaller proportion of their projects.

Table 25: Barriers to adoption and use of BIM in projects

\begin{tabular}{|c|c|c|c|c|c|c|c|c|}
\hline & & & \multicolumn{5}{|c|}{ What do you think is the BIGGEST barrier to BIM adoption in T\&T? } & \multirow[b]{2}{*}{ Total } \\
\hline & & & $\begin{array}{c}\text { Client } \\
\text { Demands }\end{array}$ & $\begin{array}{l}\text { Cost of } \\
\text { software and } \\
\text { training }\end{array}$ & \begin{tabular}{|l|} 
Unwillingnes \\
s to change \\
methods and \\
practices \\
\end{tabular} & $\begin{array}{c}\text { Lack of } \\
\text { awaremess }\end{array}$ & Other & \\
\hline \multirow{8}{*}{$\begin{array}{l}\text { Percentage of Projects } \\
\text { Recoded }\end{array}$} & Less than $25 \%$ & Count & 1 & 4 & 2 & 0 & 0 & 7 \\
\hline & & $\begin{array}{l}\text { \% within What do you } \\
\text { think is the } \\
\text { BIGGEST barrier to BIM } \\
\text { adoption in T\&T? }\end{array}$ & $50.0 \%$ & $80.0 \%$ & $33.3 \%$ & $0.0 \%$ & $0.0 \%$ & $41.2 \%$ \\
\hline & $25 \%-50 \%$ & Count & 0 & 0 & 1 & 0 & 0 & 1 \\
\hline & & $\begin{array}{l}\text { \% within What do you } \\
\text { think is the } \\
\text { BIGGEST barrier to BIM } \\
\text { adoption in T\&T? }\end{array}$ & $0.0 \%$ & $0.0 \%$ & $16.7 \%$ & $0.0 \%$ & $0.0 \%$ & $5.9 \%$ \\
\hline & $50 \%-75 \%$ & Count & 1 & 0 & 0 & 1 & 0 & 2 \\
\hline & & $\begin{array}{l}\text { \% within What do you } \\
\text { think is the } \\
\text { BIGGEST barrier to BIM } \\
\text { adoption in T\&T? }\end{array}$ & $50.0 \%$ & $0.0 \%$ & $0.0 \%$ & $33.3 \%$ & $0.0 \%$ & $11.8 \%$ \\
\hline & $75 \%-100 \%$ & Count & 0 & 1 & 3 & 2 & 1 & 7 \\
\hline & & $\begin{array}{l}\% \text { within What do you } \\
\text { think is the } \\
\text { BIGGEST barrier to BIM } \\
\text { adoption in T\&T? }\end{array}$ & $0.0 \%$ & $20.0 \%$ & $50.0 \%$ & $66.7 \%$ & $100.0 \%$ & $41.2 \%$ \\
\hline \multirow[t]{2}{*}{ Total } & & Count & 2 & 5 & 6 & 3 & 1 & 17 \\
\hline & & $\begin{array}{l}\text { \% within What do you } \\
\text { think is the } \\
\text { BIGGEST barrier to BIM } \\
\text { adootion in T\&T? }\end{array}$ & $100.0 \%$ & $100.0 \%$ & $100.0 \%$ & $100.0 \%$ & $100.0 \%$ & $100.0 \%$ \\
\hline
\end{tabular}

\section{Discussion}

In light of the findings and the research gathered in the Literature Review, the objectives of the study; to assess the scope and extent of the implementation of BIM in the practice of architecture in T\&T, to identify and evaluate the challenges and benefits of employing BIM in the practice of architecture in T\&T, to identify and assess cultural attitudes affecting the shift to a BIM workflow in the practice of architecture in $T \& T$ can be assess in order make conclusions upon further research can be built.

Objective 1: To assess the scope and extent of implementation of BIM in the practice of Architecture in T\&T.

Collectively, the responses indicate that although the majority of Architects surveyed were wellestablished professionals who had over 20 years of professional practice and worked in medium size limited liability companies, more than half (55\%) had never used BIM. Despite a high awareness of BIM amongst this group, approximately $90 \%$ stated that they were either somewhat familiar $(29 \%)$, or very familiar $(61 \%)$ with BIM, less than half $(45 \%)$ of the respondents revealed that they had ever used it on a project.

Analyzing the data, we see a positive correlation between the Architect's level of familiarity with BIM and the length of time that they have been using BIM. Architects that have a high level of 
familiarity with BIM also, claim to use BIM in more than $75 \%$ of their projects. Familiarity with BIM was also directly linked to the extent to which BIM is used, not at one stage of the design process, but also at more than one of the stages.

Bew-Richards BIM Maturity model (2008) was used to further analysis the data. Figure 5 illustrates the various levels of BIM implementation in an organization; with level zero representing non-BIM use; and level three representing full-integrated BIM use (Richards 2008).

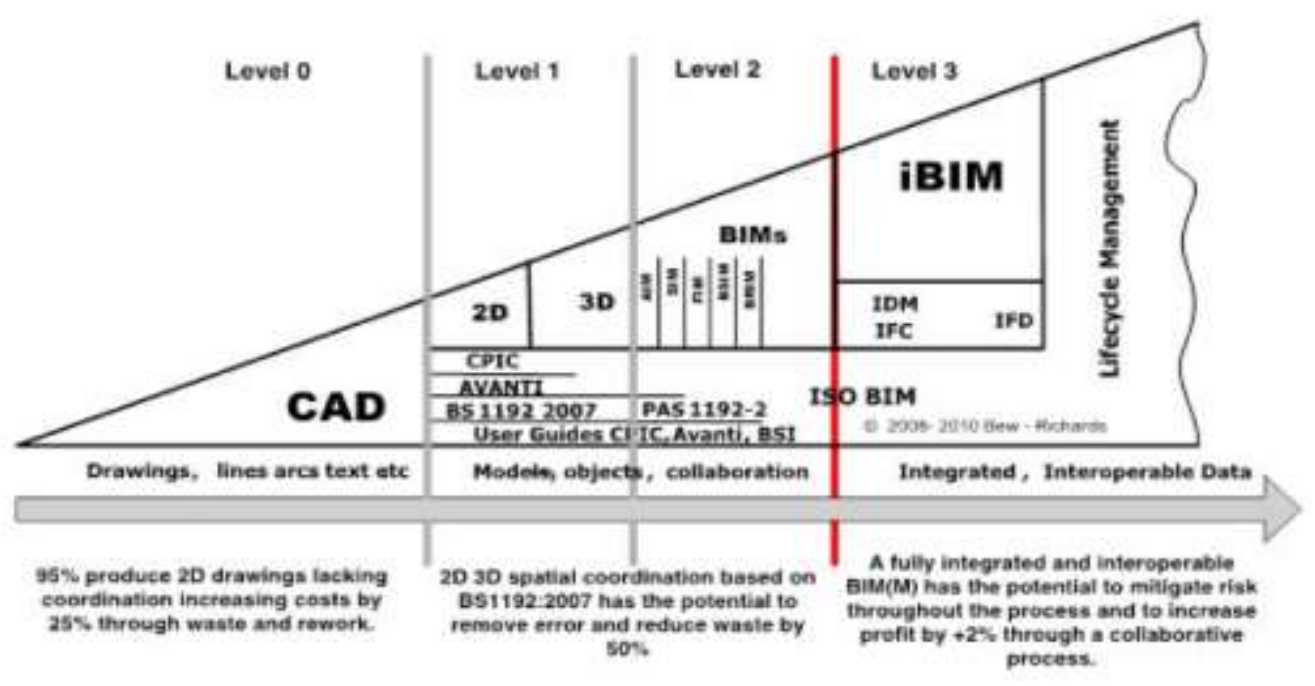

Figure 5: Bew-Richards BIM Maturity Model [11]

Based on the data, we can deduce that $55 \%$ of local Architects can be categorized as level 0 BIM since architects not using BIM would be using 2D CAD-based or other methods of managing their design information. On the other hand, $45 \%$ of Architects who stated that they have used BIM would be between level 1-2 since none of the respondents indicated using lifecycle management of BIM, which is an essential criterion for BIM Level 3. It was noted that none of the participants in the Focus group discussion mentioned any awareness of firms that uses BIM in a totally integrated and collaborative manner comparable to Level 3.

Objective 2: To identify the challenges and benefits of employing BIM in the practice of architecture in $T \& T$

A common theme within the focus group discussion was the improved early collaboration between consultants working on the project. Additionally, BIM improves the level of understanding of the project between consultants - each of who have different technical expertise - to have common understanding and communicate the scope of the project. Collaboration to achieve the desired end result is facilitated by the visual nature of BIM. The visual nature of BIM also enhances the Architect's ability to effectively communicate with clients. One focus group participant stated that clients respond positively to detailed representations of their vision and they are less likely to be unsure of the final outcome. Architects can use the BIM to get the approval and support of the client through presentation of visuals. Local architects that work in small to medium firms, highlighted the benefit that BIM brings in reducing the number of human resources required to complete a single project. This benefit allows for a more level playing field, whereby smaller 
groups of architects now have the ability to deliver on complex, larger projects, which they previously could not have accessed due to limited human resources. This allows the market to be more competitive and leads to improved levels of design and construction nationally. BIM allows Architects to assess and consider 'real world' physical properties such as energy efficiency or maintenance of the building before construction. This functionality brings benefits to the design as details can be calculated more accurately, leading to improved end product.

On the other hand, though general awareness of BIM is common among local architects, formal training is not common. Seventy-six per cent of BIM users indicated that they learnt about BIM through online training material. Currently, BIM is not included in the curriculum of traditional technical/vocational institutions. These institutions, for example, the University of Trinidad and Tobago, specifically the programs at the John Donaldson Campus, play a key role in capacity building in technical fields such as drafting, surveying and other technical areas in the construction industry. Focus group participants highlighted disconnect between local training programs and the needs of the industry. Participants highlighted the need for government to play a role in developing training programs in areas such as BIM. Architects viewed training as a financial burden both to individual practitioners and firms due to the on-going training needed and the length of time required to learn the complexities of the software. As BIM implementation is not fully implemented across AEC companies in T\&T, there arises a situation whereby some architects employ BIM, but are unable to leverage the full benefits of the model because other AEC colleagues may be using BIM systems at different stages and according to different standards to work on the same project; this may lead to several redundancies within the BIM model. The lack of a BIM policy or agreed upon standard, is a challenge to the effective implementation. Furthermore, resistance to adopt BIM from AEC colleagues is a prevalent challenge. Traditional CAD methods are the dominant methods used across the industry and there is hesitation to adopt BIM since the benefits are not fully understood locally. The data from the survey revealed that $35 \%$ of architects sighted an unwillingness to change traditional methods as an impediment to BIM use, while $75 \%$ of Architects who do not use BIM stated that they were satisfied with their current method of production. Focus group participants emphasized that motivation to adopt BIM is dependent on the requirements of clients. The government is the largest client in the local construction landscape and funds most of the construction in the country; however, there is very limited or no BIM requirement for these projects. A focus group participant, who represents the government policy-making arm for architecture in the Ministry of Works and Infrastructure, claimed that this was due to a lack of awareness of BIM within the government's construction agencies. Architects described that great emphasis is place in their practice on responding to request for proposals (RFPs) and completing government projects, which do not require BIM. Many Architects admitted that the current benefits of BIM are theoretical and they are unable to get past their immediate need for getting projects in the door and completed. Local firms are hindered by the 'hand to mouth' cycle and have difficulty seeing beyond the short-term reality of running an architecture practice.

Objective 3: To identify and assess cultural attitudes affecting the shift to a BIM workflow in the practice of architecture in $T \& T$

Successful implementation of any technology is dependent on the attitude of the people whose task it is to adopt and integrate it into their workflow. The research reveals a mixture of both optimistic perspectives towards BIM, as well as sceptical attitudes. 
The majority of Architects in the focus group were convinced that the implementation of BIM would facilitate better-built infrastructure and environments. One Architect pointed out the prospect of BIM being used for energy analysis in order to lead the way for a green movement in the industry, while another one mentioned its potential for facilities management to assist in the efficient maintenance of buildings. The findings from survey question 20 indicate that $94 \%$ of Architects believe that BIM improves the quality of the end product for either some projects $(41 \%)$ or all projects $(53 \%)$.

The survey data reveals that $76 \%$ of Architects who use BIM believe that it gives them an advantage over competitors in productivity for either some projects $(52.9 \%)$ or all projects (23.5\%). Additionally, one focus group participant supported this perception by stating that if local Architects did not adopt BIM the government will continue to hire foreign Architects who use it.

On the other hand, unlike developed countries such as the United States, there is little support for BIM on the national level in Trinidad and Tobago. The literature review points out that in the leading countries in BIM adoption, government initiatives are a major reason for its success. However, from the focus group discussion it was noted that local government institutions are unwilling to require BIM on state projects. One of the representatives from the Ministry of Works (MOW), the state body responsible for the development of infrastructure, stated that MOW did not require BIM on request for tenders (RFT) because it would inhibit too many companies from bidding. Essentially, MOW's decision to use BIM on state projects depends on its popularity in the private sector. The question arises of who should be responsible to propelling BIM implementation.

Several focus group participants voiced their concern that other AEC consultants seem to lack interest in using new technology to innovate and improve productivity. As mentioned previously, there is little external persuasion from the client or government for BIM and no real impetus for practitioners to switch from their 'tried and true' system even if it promised to be more efficient.

One focus group participant pointed out that other AEC practitioner's negative attitude towards emergent technology such as BIM affects its adoption in the local construction industry. Additionally, another participant stated that there is a fear that BIM will make the CAD systems and technicians obsolete. Many firms have built up high levels of expertise, 2D object block libraries and skilled human resource in CAD. Implementing BIM means recreating a new system with fundamental changes to their workflow and retraining staff. At the same time, they still have to be concerned about securing the next project as well as finishing current ones. This aspect of constantly chasing work and barely meeting deadlines is a reality in the construction industry and affects the implementation of new technology as stated by some architects. The findings from survey question 21 reveal that the majority of Architects (35\%) believe that the biggest barrier to BIM adoption in T\&T was individuals' unwillingness to change methods and practices.

The majority of early adopters of BIM have continued to use it in their practice and have extensively converted to a BIM workflow. However, in the focus group discussion one of these early adopters was the most pessimistic about the future of BIM in the local construction industry. His dissatisfaction stemmed from not reaping the anticipated economic returns on the effort and resources put out by his company to implement BIM. He stated that using BIM did not give him any competitive advantage in the industry, as clients did not appreciate the higher level of design analysis and quality assurance offer by BIM over traditional CAD. Additionally, the data from the 
survey revealed that $53 \%$ of Architects did not believe that the local construction industry was ready for BIM.

Local Architects are hesitant to invest in new technology such as BIM due to the unreliability of the funding of projects. One focus group participant pointed out that there is potential risk in using $\mathrm{BIM}$ on a project that does not have secured funding. BIM requires upfront investment in design planning in order to save time and cost when the building is being constructed. However, if the project stops midstream in development due to lack of financing then the intended cost and efficiency gains will never be realized.

\section{Conclusion}

The implementation of BIM in the practice of Architecture in Trinidad and Tobago has been slow and challenging. From the literature review we see that this phenomenon is not unique to this context, but also many countries, both developed and developing, experience similar problems. The most significant feature of BIM technology, the ability for information to be integrated into a single 3D model by various independent sources, is at the same time the reason for its slow adoption.

There are several other factors that contribute to the lack of awareness and slow rate of adoption of BIM in the practice of architect in T\&T. Firstly, although the majority of Architects have some idea about this emerging technology, very few truly know the difference between a BIM workflow versus traditional CAD. As seen in the data, many firms adopt BIM because it is an efficient method of producing drawings that involves less time and energy in modifying or changing a design. However, to see significant benefits of BIM, AEC consultants have to collaborate with each other using this technology and promote its widespread adoption across the entire construction sector.

The focus group discussion uncovered that many of the early adopters of BIM felt that using BIM did not give them any competitive advantage and they have not seen a return on investment on the costs of training and licensing to change to BIM. On the other hand, although some practitioners expressed awareness of the benefits of using BIM, in the same instance they expressed reluctance to change from CAD due to the uncertainty of its economic benefits in the short-term. Although, economic constraints and the tough cycle of the construction industry are deterrents, participants highlighted socio-cultural issues, fear of adopting a new technology and the accompanying paradigm shift as the greatest obstacle to BIM adoption in our local context.

Another factor that affects BIM adoption is widespread satisfaction of local AEC consultants' use of traditional CAD. Some practitioners viewed BIM as an unnecessary tool or luxury, which adds limited value to the end product. The literature points out that in almost all cases BIM is reduced to traditional 2D for submission for approvals and construction. Additionally, many clients are unaware of the benefits of using BIM over CAD and are not willing to pay more. Also, given compatibility problems associated with working in a platform counter to the norm, which is currently AutoCAD, many firms do not see the benefit of adopting BIM.

Furthermore, deficiencies in the construction industry, such as labour and material mismanagement of resources, are independent of the design consultant's work that can cause projects to have cost and time overruns. Poor quality of workmanship and lack of skilled labour has a major effect on the finished product. BIM offers very little to solve these critical problems 
in the industry. It has been argued by some interviewees that improving the production of design information while other factors remain the same does not necessarily improve the end product.

In summary, BIM requires a higher level of collaboration among the construction disciplines than was previously required by any other technology. The full potential of BIM cannot be realised if used independently by practitioners, and although there are many factors that influence the issue of its adoption, one of the most significant is the resistance to change from the current method of working in silos to a more collaborative approach of sharing information on construction projects. All parts of the supply chain have to fully support the implementation of this emerging technology in order to see the real benefit that it could bring to the construction industry. This study established a basis for understanding how BIM is currently used in the practice of Architecture in T\&T, which offers some insight into BIM adoption for the entire construction industry.

\section{References}

[1] S. Azhar, A. Nadeem, J. Y. N. Mok, and B. H. Y. Leung. 2008. "Building Information Modeling (BIM): A new paradigm for visual interactive modeling and simulation for construction projects." Proc., First International Conference on Construction in Developing Countries.

[2] V. Bazjanac. 2004. "Virtual building environments (VBE)-applying information modeling to buildings." EWork and EBusiness in Architecture, Engineering and Construction: Proceedings of the 5th European Conference on Product and Process Modelling in the Building and Construction Industry: ECPPM 2004, 8-10 September 2004, Istanbul, Turkey.

[3] H. S. Jayasena and C. Weddikkara. 2012. "Building Information Modeling for Sri Lankan Construction Industry." Proceedings of World Construction Conference 2012: Global Challenges in Construction Industry.

[4] N. Gu and K. London. 2010. "Understanding and facilitating BIM adoption in the AEC industry." Automation in Construction 19 (8):988-999. http://dx.doi.org/10.1016/j.autcon.2010.09.002.

[5] M. Yalcinkaya and V. Singh. 2015. "Patterns and trends in building information modeling (BIM) research: A latent semantic analysis." Automation in Construction 59: 68-80.

[6] P. E. Connolly. 2009. "CAD software industry trends and directions." Engineering Design Graphics Journal 63 (1).

[7] D. B. Thompson and R. G. Miner. 2006. "Building information modeling-BIM: Contractual risks are changing with technology." [Available at: http://www.aepronet.org/ge/no35.html].

[8] N. Golafshani. 2003. "Understanding reliability and validity in qualitative research." The Qualitative Report 8 (4): 597-606.

[9] K. B. Wright. 2005. "Researching Internet-based populations: Advantages and disadvantages of online survey research, online questionnaire authoring software packages, and web survey services." Journal of Computer-Mediated Communication 10 (3) https://doi.org/10.1111/j.10836101.2005.tb00259.x

[10] G. Keller, B. Warrack, and H. Bartel. 1994. Statistics for management and economics: Brooks/Cole.

[11] M. Bew and M. Richards. 2008. "Bew-Richards BIM maturity model." BuildingSMART Construct IT Autumn Members Meeting, Brighton 